\title{
O CRETÁCEO INFERIOR NAS BACIAS SEDIMENTARES DA COSTA SUDESTE DO BRASIL: ANÁLISE ISOTÓPICA E SUAS IMPLICAÇÕES PALEOAMBIENTAIS
}

\author{
RENÉ RODRIGUES* e TIKAE TAKAKI*
}

\begin{abstract}
Carbon isotope data of bitumen, and carbon and oxygen isotope data of limestone provided additional knowledge to the sedimentation environment of the Lower Cretaceous sedimentary sequences of Campos and Espírito Santo basins. In the Buracica stage the carbon isotope data of bitumen suggest a deposition in fresh water lake. The isotope data of bitumen and limestone from lower and middle section of Jiquiá stage could indicate a sedimentation in fresh water lake but gradually more saline on the top. More positive $\delta^{13} \mathrm{C}$ values of limestone in the upper portion of the Jiquiá stage and in the Alagoas stage suggest a restrict marine environment or deposition in hippersaline lakes. During the Albian, the carbonate sedimentation could have occurred still in a marine environment and above normal salinity. According to $\delta^{18} \mathrm{O}$ data, the surface waters were warm, with a tendency to become gradually cooler towards the top of Albian.
\end{abstract}

INTRODUÇÃo Os valores da relação isotópica do carbono do betume (matéria orgânica solúvel no diclorometano) presente nos folhelhos são funções, basicamente, do tipo de matéria orgânica que lhe deu origem e do meio em que se desenvolveu essa matéria orgânica. Secundariamente, esses valores são afetados pela temperatura em que se processou a formação do betume.

Para os calcários, os valores da relação isotópica do carbono e oxigênio também dependem do ambiente de formação desses carbonatos. Como a calcita e a dolomita secundárias nem sempre se formaram em condições idênticas às dos carbonatos primários, é possível obter informações não só do ambiente de deposição dos sedimentos originais mas também das condições em que ocorreram as modificações diagenéticas posteriores.

E exatamente em torno dessas possibilidades de aplicações que são apresentadas e discutidas as implicações paleoambientais dos resultados isotópicos obtidos no estudo do Cretáceo Inferior das bacias sedimentares de Campos e Espírito Santo.

Essa reconstituição paleoambiental do Cretáceo Inferior complementa os dados e interpretações de Takaki \& Rodrigues (1984).

A localização da área considerada neste estudo é apresentada na figura 1 .

MEDIDAS As medidas das relações isotópicas das amostras foram efetuadas em relação a um padrão secundário, ajustado ao padrão internacional PDB (carbonato padrão: belemnite da Formação Peedee, Cretáceo Superior, Carolina do Sul, EUA).

Os dados isotópicos são representados pela notação $\delta$, que é definida como:

$$
\delta \%=(R a-R p) / R p \times 10^{3},
$$

em que $R a$ e $R p$ se referem às relações ${ }^{13} \mathrm{C} /{ }^{12} \mathrm{C}$ ou ${ }^{18} \mathrm{O} /{ }^{16} \mathrm{O}$, respectivamente, da amostra e do padrão.

\section{APRESENTAÇÃO E DISCUSSÃO DOS RESULTADOS Andar Buracica Por se tratar de uma seqüência essen-}

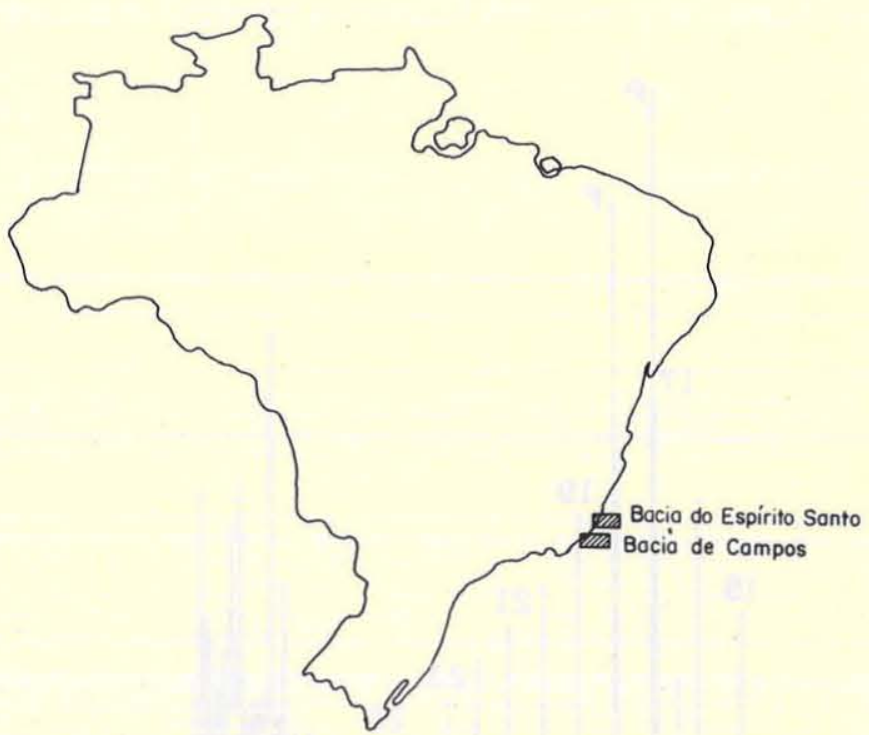

Figura 1 - Mapa de localização das bacias estudadas

cialmente argilosa, apenas foram efetuadas determinações isotópicas $\left(\delta^{13} \mathrm{C}\right)$ do betume presente nos folhelhos.

Os valores de $\delta^{13} \mathrm{C}$ mais negativos que $-28 \%$ o caracterizam uma origem a partir de matéria orgânica presente em lagos de águas doces. A maior proporção de pristano (P) em relação ao fitano (F) observada no cromatograma também é indicativa de matéria orgânica continental (Figs. 2 e 3).

O teor de carbono orgânico total entre $2,0 \%$ e $4,0 \%$ caracteriza um ambiente rico em matéria orgânica e um meio redutor capaz de tê-la preservado (Fig. 2). Os resultados das análises de pirólise e carbono orgânico, representados pelos índices de hidrogênio (mg de hidrocarbonetos/g de carbono orgânico) e oxigênio ( $\mathrm{mg}$ de $\mathrm{CO}_{2} / \mathrm{g}$ de carbono orgânico), sugerem a predominância de matéria orgânica do tipo II (Epistalié et al. 1977), que propicia a geração de óleo e gás (Fig. 4). 


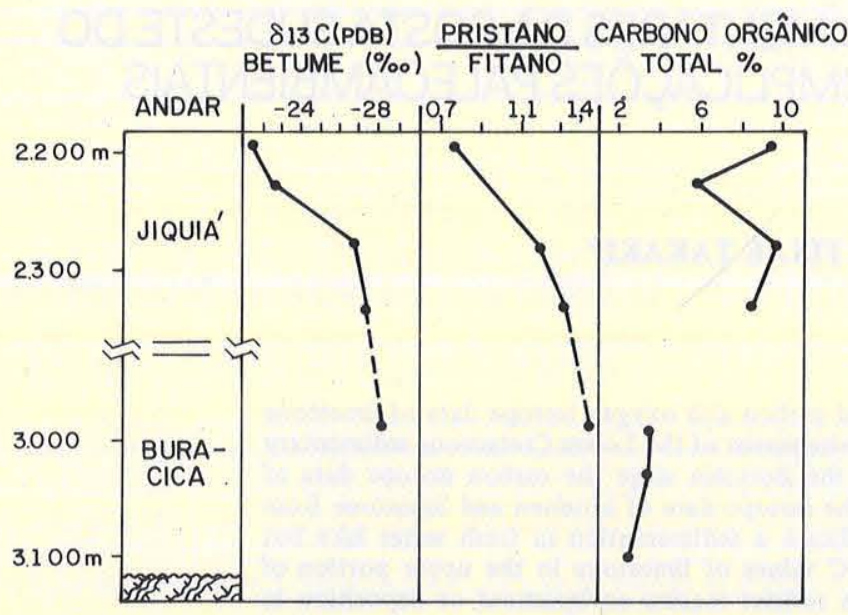

Figura 2 - Dados das análises isotópica $\left(\delta^{13} C\right)$, cromatográfica (relação pristano/fitano) e de carbono orgânico total dos andares Buracica e Jiquiá

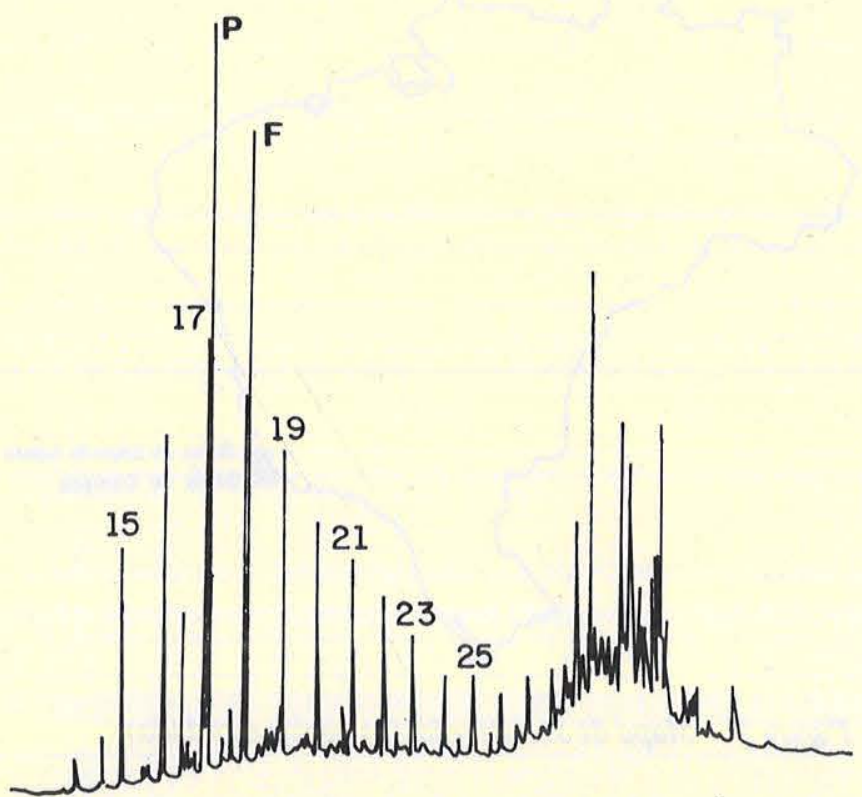

Figura 3 - Exemplo de cromatograma do betume extraido na base do Andar Jiquiá. $P=$ pristano; $F=$ fitano; 15,17 , 19... parafinas normais com $15,17,19 \ldots$ atomos de carbono na estrutura

Andar Jiquiá Este andar é constituído, essencialmente, de folhelhos na seção basal e de calcários com intercalações de folhelhos em sua parte superior.

$\mathrm{Na}$ sequêencia inferior argilosa, os dados de $\delta^{13} \mathrm{C}$ do betume mostram uma nítida variação, passando de valores mais negativos na base $(-27,5 \%)$ para menos negativos no topo $(-21,3 \%$ ) (Fig. 2). Essa modificação, também observada nos valores da relação pristano $(\mathrm{P}) /$ fitano $(\mathrm{F})$, que diminuem de 1,32 para 0,75 , sugere uma deposição em lago gradativamente mais salino e talvez mais redutor da base para o topo dessa seqüência argilosa.

Já na seção carbonática inferior e média do Andar Jiquiá (zona paleontológica RT-0093), os valores de $\delta^{13} \mathrm{C}$ e $\delta^{18} \mathrm{O}$ situam-se entre $1,0 \%$ e $-1,0 \%$ (Figs. 5 e 6). Esses valores indicam, no gráfico de Keith \& Weber (1964), um ambiente marinho com salinidade normal. No entanto, a ausência de fósseis marinhos (Moura \& Praça 1985), que deveriam ser esperados em tais condições, descarta essa possibilidade. Assim, conforme indicam os dados de $\delta^{13} \mathrm{C}$ do betume da sequêencia basal (Fig. 2), o processo de gradativa salinização de um lago poderia explicar o fato de os valores de $\delta^{13} \mathrm{C}$ e $\delta^{18} \mathrm{O}$ dos carbonatos serem semelhantes aos observados em calcários depositados em ambiente marinho normal: durante o processo de salinização dos lagos, normalmente ocorre uma deficiência de $\mathrm{CO}_{2}$ derivado biologicamente (rico em ${ }^{12} \mathrm{C}$ ) e a eliminação de ${ }^{16} \mathrm{O}$ durante a evaporação, possibilitando a formação de calcários isotopicamente mais pesados, com valores próximos dos encontrados em calcários marinhos.

Em direção ao topo do Andar Jiquiá (zona paleontológica RT-010), os valores de $\delta^{13} \mathrm{C}$ dos calcários tornam-se abruptamente mais positivos (Figs. 5 e 6 ). Este fato poderia indicar uma incursão marinha ou um processo de rápida hipersalinização do lago.

Andar Alagoas Os poucos calcários ocorrentes nesta seqüência mostraram, na base, valores de $\delta^{13} \mathrm{C}$ e $\delta^{18} \mathrm{O}$ semelhantes aos constatados no topo do Andar Jiquiá, mas com tendência a serem mais positivos em direção ao topo do Andar Alagoas (Fig. 6). Este último dado poderia sugerir um incremento das condições de evaporação, o que teria possibilitado a precipitação das camadas de sais no topo do Andar Alagoas.

Andar Albiano Os dados isotópicos dos calcários, excetuando a seção denominada "Bota", mostram pequenas variações, com valores de $\delta^{13} \mathrm{C}$ entre $+3,0 \%$ e $+4,0 \%$ 。 (Figs. 5 e 6). Estes valores bastante positivos e com poucas flutuações são indicativos de um ambiente marinho com salinidade acima da normal.

Os valores de $\delta^{18} \mathrm{O}$ para esse mesmo pacote variam de $-6,0 \%$, na base, a $-3,0 \%$, no topo, sugerindo a ocorrência de águas quentes, mas com tendência gradual a resfriamento da seção basal para a seção superior do Albiano (Figs. 5 e 6 ).

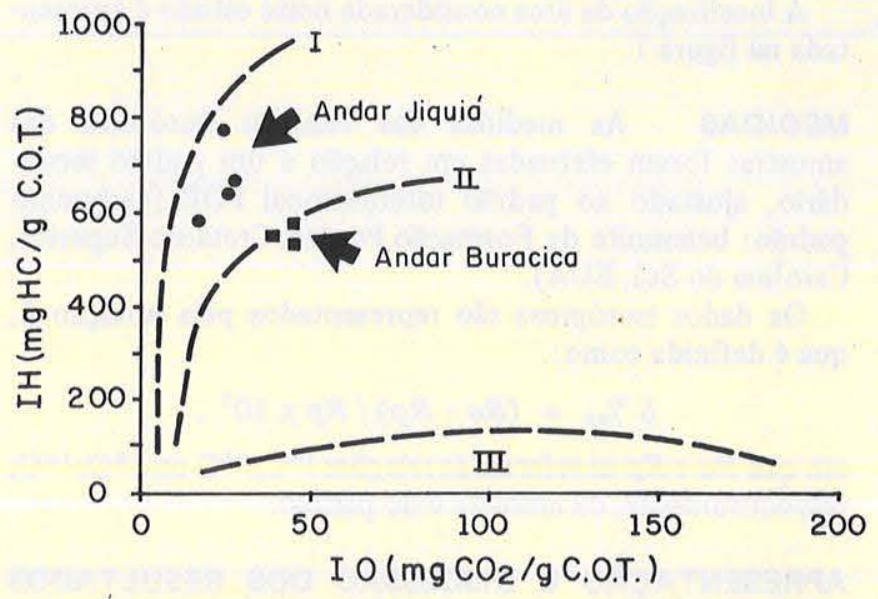

Figura 4 - Diagrama tipo Van Krevelen dos andares Buracica e Jiquiá. $I H=$ indice de hidrogênio; $I O=$ indice de oxigênio 


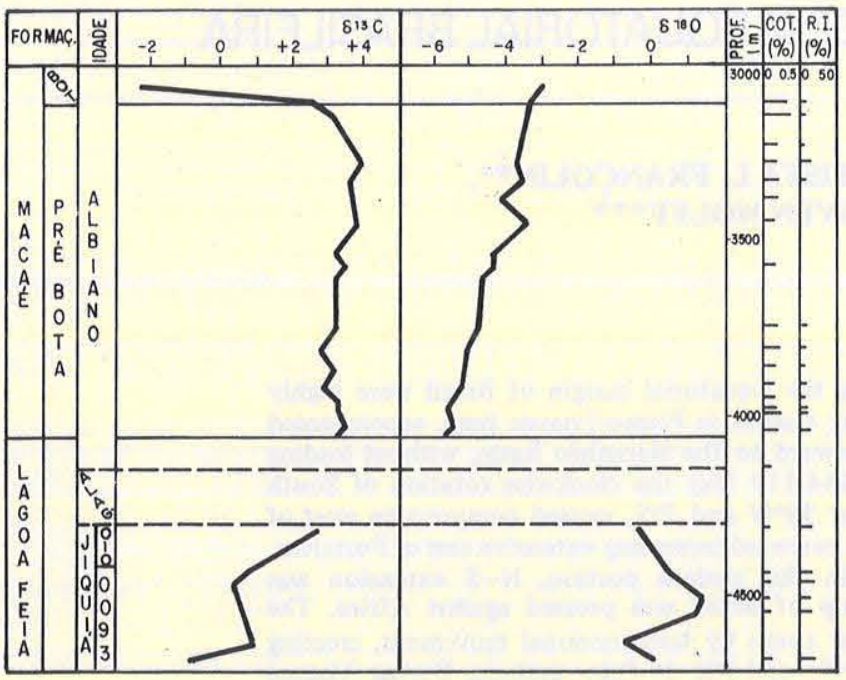

Figura $5-$ Dados de $\delta^{13} C, \delta^{18} O$, teores de carbono org $\hat{a}$ nico total e residuo insolúvel dos calcários

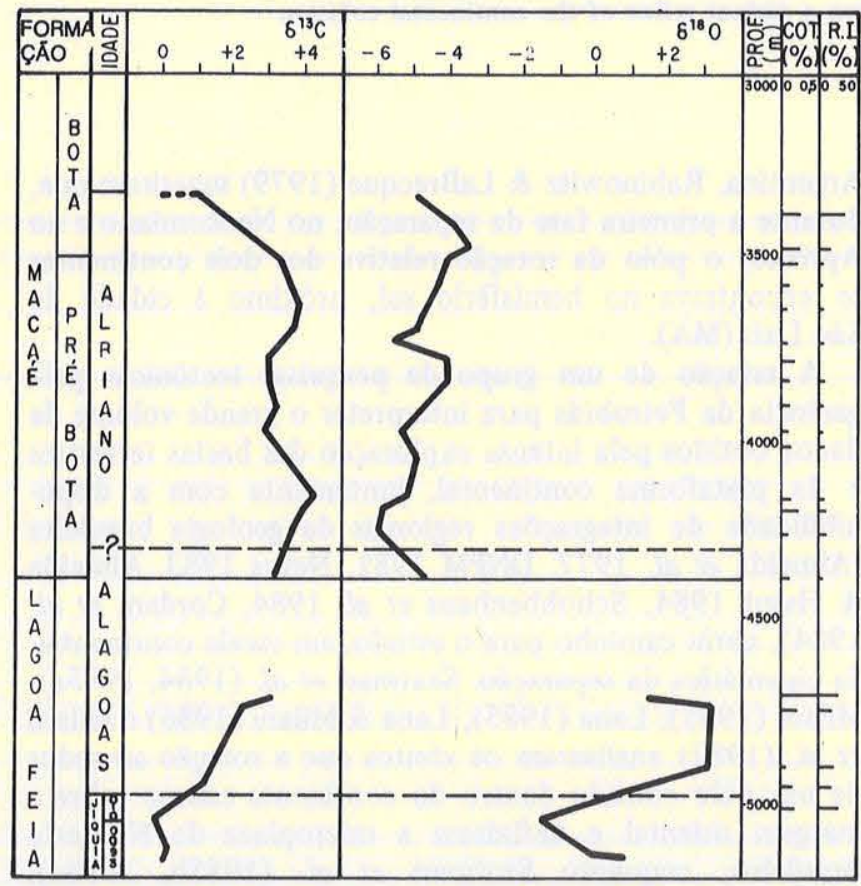

Figura 6-Dados de $\delta^{13} \mathrm{C}, \delta^{18} \mathrm{O}$, teores de carbono orgânico total e residuo insolúvel dos calcários do poço RJS-117A
Essas conclusões, que indicam ocorrência de um ambiente marinho com salinidade acima da normal durante o Albiano, também têm suporte nos dados paleoecológicos obtidos por Dias-Brito (1982).

A paulatina umidificação do clima durante o Albiano, como sugere Dias-Brito (1982), pode estar relacionada com o gradual resfriamento da água, conforme indicam os valores de $\delta^{18} \mathrm{O}$.

Nos calcários do topo do Albiano, parte da seqüência denominada "Bota", observa-se uma acentuada modificação dos valores de $\delta^{13} \mathrm{C}$, passando de $+3,0$ e $+4,0 \%$ para $+2,0$ e $-2,0 \%$.

Este fato, coincidente com a presença de maiores impurezas nos calcários e o aparecimento de folhelhos e margas intercalados, indicaria maior suprimento de detritos na área continental. Isso possibilitaria um maior influxo de águas ricas em ${ }^{12} \mathrm{C}$ derivado biologicamente, ocasionando a deposição de calcários empobrecidos em ${ }^{13} \mathrm{C}$ em relação aos calcários da seção "pré-Bota" (Figs. 5 e 6).

A presença de argila nessa parte do Albiano está relacionada com o intemperismo químico na área continental, com a respectiva drenagem dos detritos oriundos desse intemperismo para a bacia de sedimentação. Isso foi possível graças à variação de um clima quente e seco, no início do Albiano, para um clima progressivamente mais úmido e propício ao intemperismo químico em direção ao topo do Albiano, conforme evidenciam os dados isotópicos (Figs. 5 e 6) e paleoecológicos (Dias-Brito 1982).

CONCLUSÕEs Os dados de $\delta^{13} \mathrm{C}$ do betume e de $\delta^{13} \mathrm{C}$ e $\delta^{18} \mathrm{O}$ dos calcários forneceram informações adicionais sobre as condições ambientais existentes durante a deposição do Cretáceo Inferior da costa sudeste do Brasil.

O Andar Buracica foi caracterizado por uma deposição num ambiente lacustre de água doce.

Para o Andar Jiquiá, ainda prevalecem as condições lacustres, mas com águas gradativamente mais salinas a partir de sua seqüência basal.

No topo do Andar Jiquiá e no Andar Alagoas, os dados isotópicos sugerem a deposição num ambiente restrito com influência marinha ou em lagos salgados, ambos com tendência a hipersalinidade na parte superior dessa seqüência.

Durante o Albiano, a sedimentação ter-se-ia processado em ambiente marinho com salinidade acima da normal, em águas quentes, mas com gradual resfriamento para o topo desse andar.

\section{REFERÊNCIAS BIBLIOGRÁFICAS}

DIAS-BRITO, D. - 1982 - Evolução paleoecológica da Bacia de Campos durante a deposição dos calcilutitos, margas e folhelhos da Formação Macaé (Albiano e Cenomaniano?). Bol. Téc. Petrobrás, 25(2):75-125.

EPISTALIÉ, J.; LAPORTE, J.L.; MADEC, M.; MARQUES, F.; LEPLAT, P.; PAULET, J. - 1977 - Méthode rapide de caractérization des roches mères, de leur potential pétrolier e de leur degré d'évolution. Rev. Inst. Français du Pétrole, 32:23-42.

KEITH, M.L. \& WEBER, J.N. - 1964 - Carbon and oxigen isotopic composition of selected limestones and fossils. Geoch. Cosmoch. Acta, 28:1787-1816.

MOURA, J.A. \& PRAÇA, U.M. - 1985 - Ostracodes das seqüências não-marinhas e transicionais mesozóicas (Andares Jiquiá e Alagoas, Bacia de Campos). In: BRASIL, MME-DNPM, Coletâ- nea de Trabalhos Paleontológicos. Brasília, DNPM, p. 401-408. (Trab. apres. 80 Congr. Bras. de Paleont., Rio, 1983) (Geol. 27, Paleont. e Estrat. 2).

TAKAKI, T. \& RODRIGUES, R. - 1984 - Isótopos estáveis do carbono e oxigênio dos calcários como indicadores paleoambientais - Bacias de Campos, Santos e Espírito Santo. In: CONGR. BRAS. GEOL., 33, Rio de Janeiro, 1984. Anais... Rio de Janeiro, SBG. v. 10, p. $4750-4762$. 